\title{
Cultural Comparison for the Action of Looking At a Mobile Phone Display Focusing on Independent/Interdependent Self
}

Takashi Nakamura ${ }^{{ }^{*}}$, Adam Acar $^{2}$ and Mark Ng $^{3}$

${ }^{1}$ Faculty of Humanities, Niigata University, Japan

${ }^{2}$ Kobe City University of Foreign Studies, Japan

${ }^{3}$ Department of Business Administration, Hong Kong Shue Yan University, Hong Kong

\begin{abstract}
This paper focused on the action of looking at a mobile phone display as a type of nonverbal behavior/ communication and compared it cross-culturally. The diversity of nonverbal behavior/communication was considered to be caused by the difference between Western and non-Western cultures. The questionnaire was conducted in three countries (the USA, Hong Kong and Japan), and a total of 309 subjects participated. The participants were required to record their opinions for the action according to the situation with 'co-present' familiar persons. The analysis declared that the difference between the USA and Japan was more pronounced as the relationship with the 'co-present' person was more intimate. The results of the Hong Kong sample were intermediate between those of the other two countries. The diversity was discussed in terms of independent/interdependent self in the perspective of cultural comparison and of mobile phone usage. The analysis revealed that the action as a form of nonverbal behavior/communication has functioned in human relationships and has been deeply embedded into culture in the mobile phone era.
\end{abstract}

Keywords: Mobile phone; Independent; Nonverbal Behavior; Interdependent; Communication; Smartphones

\section{Highlights}

The action to look at a mobile phone display was cross-culturally compared.

Questionnaire was conducted in the USA, Hong Kong and Japan.

The difference among the three countries was detected according to intimacy.

The common feature was supported by the power of sight line.

Independent/interdependent self-construal is redrawn with embedded mobile phones.

\section{Introduction}

In 2014, the ITU reported that the number of mobile cellular subscriptions for developed and developing countries had, respectively, reached 1.5 billion and 5.4 billion, which corresponds to approximately $120 \%$ and $90 \%$ per inhabitants. Almost all people have their own mobile phone (including smartphone users in this study), and the rate of high spec mobile phone use has definitely increased. According to an IDC press release, worldwide smartphone shipments will reach a total of nearly 1.3 billion units in 2014, representing an increase of $26.3 \%$ over 2013. High-spec mobile phones, including smartphones, need/compel a user to operate them because they have a variety of functions. Then, many users frequently look at their mobile phones to use them, and, consequently, people often see someone look at his/her mobile phone display during their daily lives.

It is obvious that the number of people looking at their own mobile phone display has increased everywhere, although such people were observed very rarely in the 1990s. People who look at their mobile phone display to use various functions in public spaces are apt to pay less attention to their surroundings and, unfortunately, sometimes cause traffic accidents. Much research has been performed to warn about mobile phone use in public spaces in order to prevent careless tragedies for drivers and for pedestrians [1-4]. Furthermore, the action to look at a mobile phone display seems to be closed and unsociable. Such an impression should push much conservative research to criticize mobile phone usage in front of other people. Conversely, there have been affirmative studies claiming that mobile phone usage in public spaces can be connected to new social and cultural activity [5-7]. Researchers anticipated the development of culture and social relations by locational use of mobile phones.

Nakamura studied the function and/or meaning of the action to look at a mobile phone display. He interpreted this action as nonverbal behavior/communication, referring to face-to-face interaction theory [8-10]. Additionally, Ayab discussed mobile phone usage in public spaces, concluding that the mobile phone can be utilized as an involvement shield [11]. According to Goffman's view, public spaces can be considered a common ground for communicating with nonverbal signals, most of which are silently exchanged [12]. In the mobile phone era, texting or operating the gadget in public spaces nonverbally plays a certain role to resolve difficult situations $[6,11,13]$. Mobile phone usage in public spaces should be discussed with reference to such a 'public' role, which has been spread worldwide.

Japanese informants were surveyed to declare how they interpreted a familiar person's action to look at a mobile phone display without permission [14]. The number of informants to accept families' action was more than that for the case of a close friend or the case of plural friends. This suggests that the actions of more intimate persons should be more acceptable. Then, the question arises whether such inclination is only for Japanese culture. In this paper, the judgment for an intimate person's action to look at a mobile phone display is cross-culturally compared among the USA, Hong Kong and Japan.

*Corresponding authors: Takashi Nakamura, Faculty of Humanities, Niigata University, Japan,Tel: 81252626452; E-mail: takashi-nakamura@ human.niigata-u.ac.jp

Received August 25, 2016; Accepted August 31, 2016; Published Septembe 07, 2016

Citation: Nakamura T, Acar A, Ng M (2016) Cultural Comparison for the Action of Looking At a Mobile Phone Display Focusing on Independent/Interdependent Self. Bioceram Dev Appl 6: 095. doi: 10.4172/2090-5025.1000095

Copyright: (C) 2016 Takashi Nakamura , et al. This is an open-access article distributed under the terms of the Creative Commons Attribution License, which permits unrestricted use, distribution, and reproduction in any medium, provided the original author and source are credited. 


\section{The Action to Look at a Mobile Phone Display}

\section{Non-verbal behavior/communication}

Goffman claimed that if people are physically 'co-present' together in a space, some information will be sent by each other regardless of their intentions [12]. The human body sends various types of signals, such as height, gender, race, look, line of sight, hair, clothing, footwear, belongings, voice, tone, language, loudness, scent, and action, and 'copresent' people receive some of the signals even if they do not want to. Goffman called such perpetual and unavoidable communication 'face-to-face interaction'. Although face-to-face interaction includes verbal language communication, the human body perpetually and nonverbally releases many signals other than verbal ones. In the view of face-to-face interaction, mobile phone usage, including the action to look at a mobile phone display, should send some signals. This means that the action can be considered to be nonverbal behavior/ communication.

As summarized by Knapp et al., research for nonverbal behavior/ communication has significantly increased since the 1950s [15]. Research topics and related subjects explosively increased in the 1960s, for example, Goffman, Argyle and Dean, Hall, Kendon and so on $[10,12,16-18]$. After the 1970s, research subjects were fractionalized and ways to integrate parallel signals were theorized and research progressed to put the theories into practice for social demands $[19,20]$. Researchers have consistently focused on 'raw' physical movement, and consequently, they have not adequately addressed the action to look at a mobile phone display, which is suggestive of the user's social communication with someone else, even as recently as the 2000 s.

After the 2000s, the mobile phone has grown to contain various functions and to take on many roles; then, the opportunity to look at a mobile phone display has increased more and more. As an action that necessitates some degree of physical movement, the action to look at a mobile phone display thus necessarily involves nonverbal signals. In one case, such nonverbal signals might be released without an user's intention, such as confirmation of the current time; in another case, nonverbal signals might be sent to express (or conceal) a user's uncomfortable feelings [9]. The action to look at a mobile phone display as a form of nonverbal behavior/communication should be studied more scientifically, physically, socially and communicationtheoretically.

\section{The increase of the action}

In the mobile phone era, a user is able (or compelled) to develop/ maintain social relationships with others using his/her mobile phone everywhere. Reading/writing of text or social media is one of the typical actions to develop/maintain a user's sociality. The remarkable point of such action in the view of nonverbal behavior/communication is that the duration can be adjusted by the user. Thus, he/she can pretend to gaze at the display in order not to see what he/she does not want to see as long as necessary. When staying alone in public spaces, there are many situations not to look at or not to be stimulated, and people are inclined to look at their mobile phones even when they need no installed function in the mobile phone $[6,8,11]$.

People sometimes require the action to get through the situation not only to stay alone in public spaces but also to stay with familiar persons. Nakamura listed three motivations to look at a mobile phone display in a situation with familiar persons as follows [9];

\section{A: To check the time or receive communication notifications}

\section{B: To enhance ongoing conversations with informational anecdotes}

C: To express or conceal negative feelings or to escape from an ongoing conversation

The third motivation $\mathrm{C}$ should be emphasized. Face-to-face communication with familiar persons is not always positive. Such intentional action could be caused by the direction of a conversational topic [14]. Even staying with familiar persons, the action to look at mobile phone display as nonverbal behavior would be needed by negative types of motivations.

\section{The three categories}

The action of looking at a mobile phone display has increased. The increased occurrence of the action means that people have learned to use nonverbal behavior to cope with some types of uncomfortable situations. This suggests that the availability of such an action had been desired by people for a long time. Now, the action has been widespread and penetrated into our daily life and people often see someone in their surroundings perform the action. However, how to interpret the action is extensively different among people.

Nakamura generally classified into three categories the impression when people saw a familiar companion look at his/her own mobile phone display without permission during a face-to-face conversation [14]. The three categories were called 'Refusal' (X-group), 'Holding' (Y-group) and 'Acceptance' (Z-group). The procedure of classification is explained in Section 'Procedure of classification'. The people classified into the first X-group became angry and/or criticized the action of the companion. They blamed their companion with no hesitation and no reflection. The people in the Y-group guessed the reason why the companion did it and waited for the present. They did not immediately get angry, but they sought the reason of the companion's action or had the patience to bear it. This suggests that they really minded the companion's action to a certain degree, but they tried to understand the behavior of the companion's. The people in the Z-group paid no attention to the companion's action and did not mind. They needed neither the reason nor the patience for it. Comparing the three groups, the $\mathrm{X}$-group and the Z-group are utterly contrary to each other.

\section{Influence of culture}

Nakamura denoted the demographic distributions of the impressions for the companion's action to look at his/her own mobile phone display without permission [13]. The first feature was that the average age of the $\mathrm{X}$-group was the highest and that of the Z-group was the lowest. This is not surprising because it has been said that the younger generation was more affirmative to mobile phone usage. The second feature was that there were more females in the Y-group than males. The reason for this finding shall be studied hereafter.

Moreover, Nakamura reported that some informants felt consistently the same impression for the action and those others switched impressions for the action depending on the actor, as researched in this paper [13]. The former type of informant seemed to have a certain criterion for interpreting the action. Regarding the latter, the ways to switch were quite various. For example, some informants belonged to the X-group in the presence of multiple friends and to the Y-group in the presence of families, and the opposite was true for others. Their judgments for the action were dependent on an intimate relation with the actor. In the survey for Japanese informants, the number of participants in the Z-group in the case of families was the highest. It should be certified whether such deviation is inherent in Japanese informants or not. 
Furthermore, Nakamura declared that some informants can change their judgment for the action based on their own experiences of it [13]. They could understand their own motivations and learn to interpret actions based on their own affairs. This means that they were able to revise their own behaviors and judgments through iteration of face-to-face communication. Ultimately, people could be influenced by their own culture.

Nonverbal behavior/communication between familiar persons has been revealed to be different in many aspects among cultures, and faceto-face communication is performed during daily life within cultures [21]. It can be predicted that the judgment of the action to look at a mobile phone display in front of familiar persons should be influenced by culture. Then, cultural comparison can be expected to explain the action to look at a mobile phone display as nonverbal behavior/ communication.

\section{Independent/Interdependent Self and Mobile Phone}

\section{Western and non-western culture}

Markus and Kitayama proposed cultural theory, in which Western culture is different from non-Western culture in terms of many aspects, and the difference is caused by the self of the people [22]. They interpreted the self in Western culture as an 'independent self and that in non-Western culture as an 'interdependent self. The independent self in Western culture has faith in the inherent separateness of a distinct person and a belief in the wholeness and uniqueness of each person's configuration of internal attributes. An independent self aims to construct oneself as an individual whose behavior is organized by reference to one's own internal repertoire of thoughts, feelings and actions. The interdependent self in non-Western culture insists on the fundamental connectedness of human beings to each other and maintains this interdependence among individuals. An interdependent self recognizes that one's behavior is fairly organized by what he/ she perceives to be the thoughts, feelings, and actions of others in a relationship.

Figure 1 represents the conceptual view of an independent self and that of an interdependent self, referring to (Figure 1) in the work of Markus and Kitayama [22]. The large left circle corresponds to the self, and the smaller ones are specific others. Independent selves do not have intersections between them, and they can be labeled as 'individualist', 'egocentric', 'separate', 'autonomous', 'idiocentric' and 'self-contained'. Conversely, interdependent selves have intersections and become part of various interpersonal relationships, and they can be labeled as 'sociocentric', 'collective', 'allocentric', 'ensemble', 'constitutive', 'contextualist', 'connected' and 'relational'. Such a cross-cultural view can be supported in a broad outline by the concepts such as 'high/ low context culture' of Hall, 'intercultural communication theory' of Gudykunst\&Nishida, 'cultural dimensions' of Hofstede, and 'systematic differences in perceptional focus' of Nisbett period [23-26].

\section{Competitive behavior}

Mobile phones can connect families, friends, siblings, co-workers and acquaintances when they are not 'co-present' together. Thus, the relation between independent self and the mobile phone can be depicted as in Figure 2. Mobile phones are located in the gap among the independent selves and not merged with the selves because they are separated from each other. As shown in Figure 2, mobile phones can be interpreted as an interface for connected persons.

Consider the situation that self $\mathrm{A}$ and self $\mathrm{B}$ are 'co-present' in the same space. Both individuals can be connected with other selves situated elsewhere via mobile phones. If self B was willing to develop/ maintain a relationship with self $A$, self $B$ would feel hostile against a connection from self $\mathrm{C}$ to self $\mathrm{J}$ because they could connect to self $\mathrm{A}$ anytime and they might stand in the way of communication. If self $\mathrm{A}$ broke eye contact and performed the action to look at a mobile phone display during face-to-face conversation, self $\mathrm{B}$ would associate it with the relationships with self $\mathrm{C}$ to self J. To make trustworthy relationships, people in Western culture set a high value on direct meeting and eye contact. Thus, declining eye contact as a consequence of mobile phone use has raised social concerns, as reported in The Wall Street Journal [27]. The action necessarily interrupts eye contact in direct meeting; people would be antagonistic against the intimate person's action to look at mobile phone display in face-to-face communication.

Ultimately, the action to look at a mobile phone display can be interpreted as being competitive between independent selves in Western culture. It can be predicted that most people should get angry at their intimate persons, if the intimate persons look at their own mobile phone display during face-to-face conversation.

\section{Compatible behavior}

In non-Western culture, interdependent selves think of themselves as being defined by social relationships, and they depend on each other and voluntarily maintain connectedness [22]. In the mobile phone era, they could improve and enhance connectedness by using a mobile phone. This means that mobile phones should not only provide communication channels between them but also concern their own dependency and self-definition.

Such a view can be depicted as shown in Figure 3. Mobile phones connect the relationships between the selves; thus, it should be embedded in the intersections between the interdependent selves in Figure 3. When self B was willing to develop/maintain a relationship with self A who is 'co-present' in the same space, other selves elsewhere, from self $\mathrm{C}$ to self $\mathrm{J}$, would relate with them via mobile phones, as in the case of Figure 2. However, contrary to the independent self, self

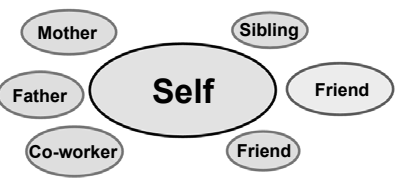

Independent Self

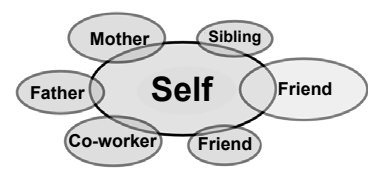

Interdependent Self
Figure 1: Conceptual representation of independent/interdependent self.

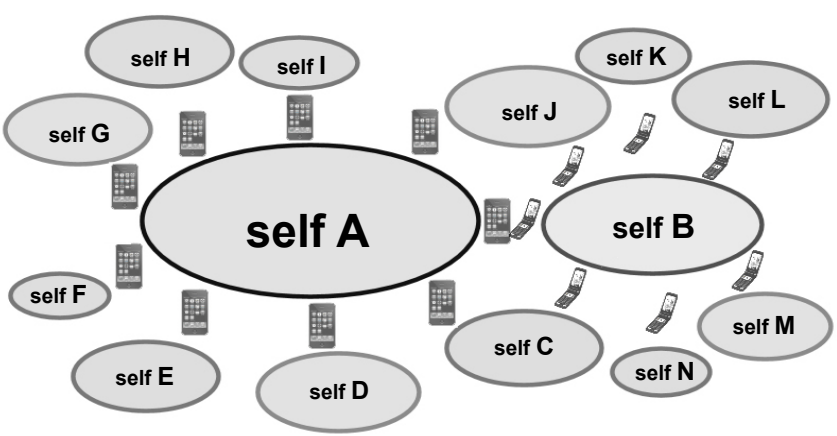

Figure 2: Conceptual representation of independent selves mediated by mobile phones. 
B would regard the other selves positively because self A consists of the other selves and is not separable from them. Even if self A broke eye contact and looked at the mobile phone display during face-to-face conversation, self $\mathrm{B}$ would still acknowledge the other selves who were brought to remembrance by the action. Thus, such actions in front of intimate persons should be acceptable in non-Western culture.

Ultimately, the action can be interpreted as compatible to interdependent selves in non-Western culture. It can be predicted that most people should not mind the action when the intimate person looks at his/her own mobile phone display during conversation even without permission. Comparing the two predictions, it can be expected that the difference in the reaction between Western and non-Western culture could be detected more clearly when the 'co-present' actor was more intimate.

\section{Survey}

\section{Subjects}

The survey was conducted in the three countries, the USA, Hong Kong and Japan. The USA is a representative country for Western culture and Japan represents non-Western culture. Hong Kong is a hybrid country of Western and non-Western cultures because people in Hong Kong can be influenced by the two divergent cultures.

The gender of all participants was female and they were 20-34 years old. Much research has indicated that female young adults tend to use mobile phones more often, and they voluntarily keep in touch with their parents and friends via mobile phone, thus, they can be expected to be the most appropriate informants to survey mobile phone usage $[28,29]$. All participants were ascertained to own their mobile phones in the questionnaire. Table 1 shows the age distribution, number, time, subject recruitment, and language for each country. There were a total of 309 subjects who completed the survey. In the USA, the informants were research monitors registered at Influencer Inc., and in Japan, they were registered at NTT-com Inc. In Hong Kong, the informants were invited to participate in classrooms of Hong Kong Shue Yan University. The questionnaire was the same as that used by Nakamura in Japanese [13]. It was translated into English and double-checked. The survey was conducted online. Pilot studies were conducted to assess an English version, and a revision was made for the USA and Hong Kong respondents.

\section{Open ended}

The questions presented to the informants were open ended. To analyze the judgment for the action to look at a mobile phone display, an open-ended question is appropriate. This is because the reason for the action cannot easily be known by observers, and some people are apt to withhold their decisions.

In many cases, why an actor looks at his/her mobile phone display is unknown due to the 'double concealment', which means that an observer cannot see the onscreen image and that he/she cannot determine whether the action was authentic or not $[8,9]$. Then, some informants were unable to decide on their opinions, and they would describe some associating and ambiguous answers for open-ended questions. Such answers mentioned the presumed reason or the conditional limit that causally related to the actor's decision, although they were a little over-described. It should be expected that such answers reflected the ambiguous stance of informants.

Open-ended questions do not seem appropriate for a large survey; however, text mining enables the researcher to obtain strict codes

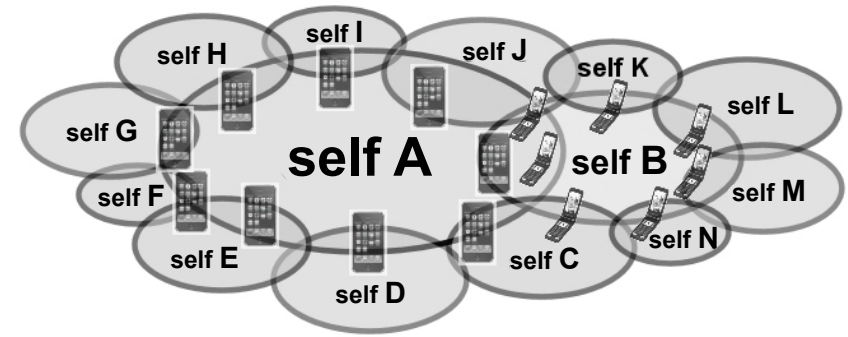

Figure 3: Conceptual representation of interdependent selves mediated by mobile phones.

\begin{tabular}{|c|c|c|c|}
\hline Variable & USA & Hong Kong & Japan \\
\hline Age distribution & $20-34$ & $20-24$ & $20-34$ \\
\hline Number & 170 & 57 & 82 \\
\hline Time & Sep, 2013 & Sep, 2013 & Mar, 2011 \\
\hline Recruitment & Mail & Oral & Mail \\
\hline Language & English & English & Japanese \\
\hline
\end{tabular}

Table 1: Properties of informants.

from open-ended texts [30]. A mining rule was able to detect such causally related (but a little over-described) answers and classify them into the separate categories. An open-ended answer is informational, and it makes it possible to be sure of the preciseness of classification. Additionally, an informant can describe his thoughts with his/her own words, even when he/she could not explicitly form an opinion. Thus, it should be expected that an open-ended question format was effective in this survey.

\section{Questions}

Three questions were asked to compare the judgments according to intimate relationships. The first question was 'Imagine that you are having a conversation with your friends. During the conversation, one of them takes out his/her cell phone and starts using it. What impression would you have of that person?' The second question was formed by replacing the phrase 'with your friends' with 'with a close friend' and replacing 'one of them' with 'he/she'. The third question was 'Imagine that one of your family members starts using his/her cellphone when you are talking or having a meal with your family. How would you feel in that situation?' The difference between the first and second questions was derived only from the companions; however, the differences in the third one are not only the companions but also the situation. The situation in the third question involves 'having a meal with your family'.

The reason why the situation of 'having a meal' was added to in the third question should be explained. To have a meal together is usual with families; however, it is more or less special with friends. The time to eat a meal is probably the longest in duration and the most important for family conversation. To estimate the situation with families, meal time should be considered together with conversation time. Furthermore, in many cultures, doing other things in the middle of a meal should be regarded as a bad manner or a breach of courtesy. Thus, it might seem that the additional situation of 'having a meal' might increase the rate of angry informants compared to the first and the second questions in all three countries. However, the only country with an increased rate of angry informants was the USA, and the rates of the other two countries decreased, as mentioned below. The situation 'having a meal' was added not only to reflect the real state to be 'co-present' with families but also to emphasize the cultural feature 
of accepting the action to look at a mobile phone display despite the manner of restriction for doing other things.

\section{Procedure of classification}

The answers of the subjects were divided into three groups using the same method as used by Nakamura and the translated one [14]. Almost all of the answers consisted of very short phrases. The way to classify them was key-word searching.

An informant was classified into the first 'Refusal' (X-group) in the following two conditions;

$\mathrm{A}_{1}$ : If his/her answer contained critical or blameful words ('disappointed', 'rude', 'bad', and 'hate', 'crazy' and so on).

$\mathrm{A}_{2}$ : If it was an interrogative sentence to doubt his/her companion's manner. ('Why?', 'She loves her telephone?' and so on).

In the answers fulfilled either condition $A_{1}$ or $A_{2}$, anger of the informants was concluded. He/she did not hesitate to criticize the companion's action.

An informant was classified into the second 'Holding'(Y-group) in the following four conditions;

B: If his/her answer contained inferential expression for his/her companion's social relations and/or unexpected job ('busy', 'need', 'urgent', 'something important' and so on).

C: If his/her answer contains inferential expression for his/her companion's negative feeling ('bored', 'uninterested', 'not listening' and so on).

D: If his/her answer contains introspective expression as if he/ she made his companion bored ('I must be boring them', 'they are uncomfortable with the conversation', and so on).

E: If his/her answer contains the expressions of acceptance for a limited time or for a limited affair ('depends on the duration', 'depends on the person', 'depends on the situation' and so on).

In the answers fulfilling one of the four conditions from $\mathrm{B}$ to $\mathrm{E}$, an uncomfortable feeling of the informants was concluded while he/ she tried to understand and regard the companion's situation. $\mathrm{He} /$ she mentioned the reason of the action to be performed or the limit to control him/herself. This suggests that he/she needed a reason for action. The questions asked included 'What impression?' or 'How would you feel?' and required neither the reason nor the limit; thus, an answer was causally related to the actor's decision but went beyond what was asked.

An informant was classified into the third 'Acceptance' (Z-group) in the following two conditions;

$\mathrm{F}_{1}$ : If his/her answer contains the expression which means a good state ('not mind', 'normal', 'ok', 'fine' and so on).

$\mathrm{F}_{2}$ : If his/her answer contains the expression which means no quality ('nothing', 'no impression', 'no special' and so on).

In the answers fulfilling either condition $\mathrm{F}_{1}$ or $\mathrm{F}_{2}$, allowance of the informants was concluded. The informants need no reason for the companion's action to look at a mobile phone display.

Some answers were very long and contained multiple sentences. Almost all of the long answers explained both discontent and respect for the companion. Such answers fulfilled more than two conditions of keyword searching. In such cases, they were preferentially classified into Y-group.
The above method can classify almost all of the answers into X-, $\mathrm{Y}-$, and $\mathrm{Z}$-groups because the questions required simple impressions or feelings toward the action of looking at mobile phones. In the Japanese survey conducted in 2009, approximately 95.9\% (4815/5019) of answers were classified into the three groups [14]. The rest did not contain even expression for causal relation to the actor's decisions. Such answers should be interpreted as the result of misreading or indolence. They were blank, made of only symbolic characters (e.g., ':-l'), meaningless responses (e.g., 'yes'), wrong understandings (e.g., 'I only call my family'), or deviate responses (e.g., 'I have no friends', 'My grandparents don't use cell phones'). They should be classified as 'others' (G-group), which was not analyzed.

In the questionnaire in this paper, the answers were able to be classified using the above method. The classification rates were $97.8 \%$ $(499 / 510)$ for the survey in the USA, 98.2\% (168/171) for that in Hong Kong, and $95.9 \%(236 / 246)$ for that in Japan.

\section{Results and Analysis}

\section{Result of classification}

The results of classification are presented in Tables 2-4 for the survey in the USA, Hong Kong and Japan, respectively. The numerical values in the cells are the actual number of informants, and the values in parentheses are the percent rates of the groups. The distributions of the rates for the countries are depicted in Figures 4-6.

Among the three countries, few informants were divided into the 'Others' (G-group) for all of the questions. The total number of informants was 309, and the percent of informants in the G-group for the three questions was approximately $2.6 \%$ (24/927). The procedure mentioned in the last section was able to classify a majority of the answers, as was seen in the work of Nakamura [14].

\section{Common features}

The most remarkable common feature among the three countries was that the rates of the 'Holding' (Y-group) of Question 1 (in front of plural friends) were comparably larger. From Figures 4-6, the rates of classified groups for Question 1 (denoted by '*') exhibited cornshaped distributions, in which the rates of the Y-group were the highest. This means that the majority of people in the three countries felt uncomfortable with the action to look at a mobile phone display but tried to understand the situation of their companions in the case of plural friends.

\begin{tabular}{|c|c|c|c|c|}
\hline USA & Refuse(X) & Hold(Y) & Accept(Z) & Others(G) \\
\hline Q1: Plural Friends & $40(24 \%)$ & $92(54 \%)$ & $35(21 \%)$ & $3(2 \%)$ \\
\hline Q2: A Close Friend & $57(34 \%)$ & $82(48 \%)$ & $27(16 \%)$ & $4(2 \%)$ \\
\hline Q3: Families & $84(49 \%)$ & $43(25 \%)$ & $39(23 \%)$ & $4(2 \%)$ \\
\hline
\end{tabular}

Table 2: Result of classification in USA.

\begin{tabular}{|c|c|c|c|c|}
\hline Hong Kong & Refuse(X) & Hold(Y) & Accept(Z) & Others(G) \\
\hline Q1: Plural Friends & $19(33 \%)$ & $29(51 \%)$ & $9(16 \%)$ & $0(0 \%)$ \\
\hline Q2: A Close Friend & $19(33 \%)$ & $27(47 \%)$ & $10(18 \%)$ & $1(2 \%)$ \\
\hline Q3: Families & $20(35 \%)$ & $14(25 \%)$ & $21(37 \%)$ & $2(4 \%)$ \\
\hline
\end{tabular}

Table 3: Result of classification in Hong Kong.

\begin{tabular}{|c|c|c|c|c|}
\hline Japan & Refuse(X) & Hold(Y) & Accept(Z) & Others(G) \\
\hline Q1: Plural Friends & $20(24 \%)$ & $32(39 \%)$ & $26(32 \%)$ & $4(5 \%)$ \\
\hline Q2: A Close Friend & $27(33 \%)$ & $26(32 \%)$ & $25(30 \%)$ & $4(5 \%)$ \\
\hline Q3: Families & $21(26 \%)$ & $18(22 \%)$ & $41(50 \%)$ & $2(2 \%)$ \\
\hline
\end{tabular}

Table 4: Result of classification in Japan. 
Citation: Nakamura T, Acar A, Ng M (2016) Cultural Comparison for the Action of Looking At a Mobile Phone Display Focusing on Independent/ Interdependent Self. Bioceram Dev Appl 6: 095. doi: 10.4172/2090-5025.1000095

Page 6 of 9

Conversely, the rates of the Y-group for Question 3 (in front of families) were smaller. In Figure 4 (USA), it was comparably lower. In Figure 5 (Hong Kong) and Figure 6 (Japan), the rates of the Y-group were the lowest except for the G-group. The difference between the rate values of the Y-group for Question 1 and that for Question 3 were significantly valid with Chi-squared test $(\mathrm{p} \sim 0.00 \%<0.1 \%$ in USA, $\mathrm{p} \sim 0.37 \%<1 \%$ in Hong Kong and $\mathrm{p} \sim 1.76 \%<5 \%$ in Japan, respectively). This means that some part of the people who were unable to decide their opinions in front of plural friends no longer hesitated in front of families. They decided to judge the action, i.e., either to refuse it with anger (X-group) or to accept it (Z-group).

In general, a relationship with families is more intimate than that with a close friend, and a relationship with a close friend is more intimate than one with plural friends (of course, there are many

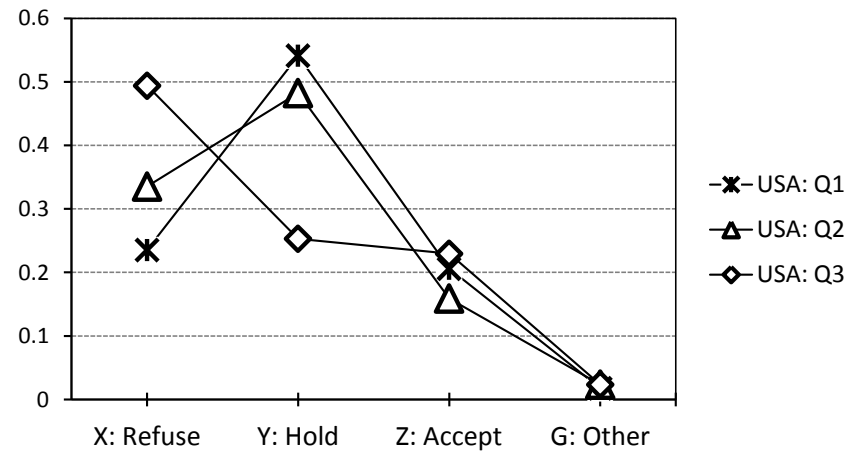

Figure 4: Distributions for the USA.

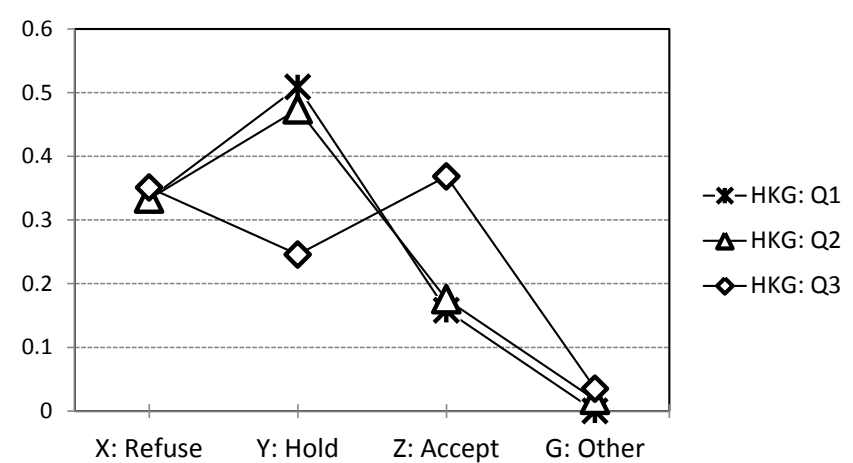

Figure 5: Distributions for Hong Kong.

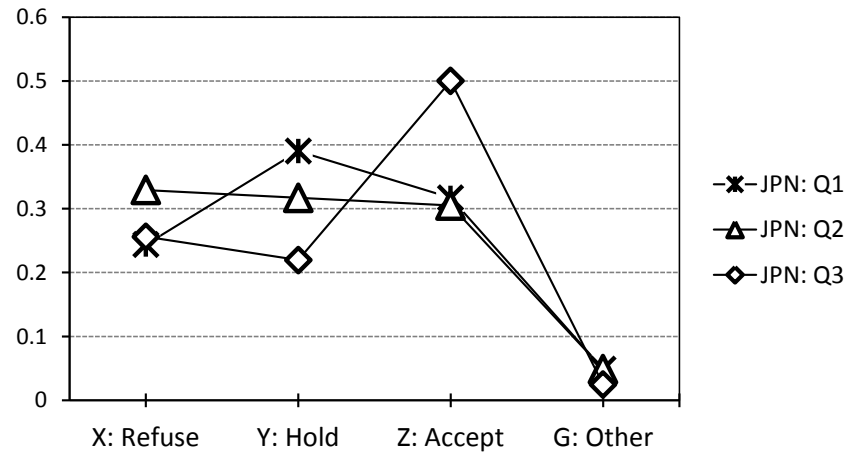

Figure 6: Distributions for Japan. exceptions); thus, as the question number increases, the intimacy of the companions increases in this survey. If the subject rate of the Y-group decreased as the question number increased in the three countries, the judgment of the action to look at mobile phone display depended on the intimacy.

\section{Distribution}

If the subject rate of the Y-group decreased as the question number increased, some of the 'members' of the Y-group in Question 1 transferred either to X-group or to Z-group in Question 3. To make clear the differential variation among the three countries, the subject rates except for the G-group should be re-depicted for each question. The distributions from Question 1 to Question 3 are plotted in Figures 7-9, respectively. In Figure 7 (for Question 1), the distributions of the three countries were similarly corn-shaped and the rate values of the Y-group were the highest, as mentioned in the last section. In Figure 8 (for Question 2), the rate values of the Y-group decreased slightly from those of Question 1. Finally, in Figure 9 (for Question 3), the rate value of the Y-group decreased for each country and the difference among the three countries was clearly demonstrated in the inclination of the distributions.

For the USA, the distribution in Figure 9 exhibits a declining shape. The difference between the value of the X-group and that of the Z-group was significantly valid, as determined using a Chi-squared test $(p \sim 0.00 \%<0.1 \%)$. The rate value of the $\mathrm{X}$-group was remarkably large, whereas that of the Z-group remained small. The difference between the value of the X-group for Question 1 and that for Question 3 was significantly valid, as determined using a Chi-squared test

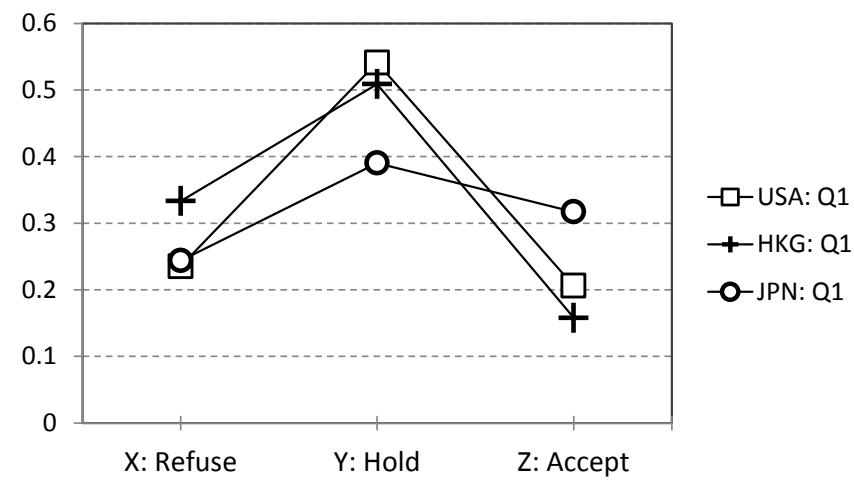

Figure 7: Distribution for Question 1.

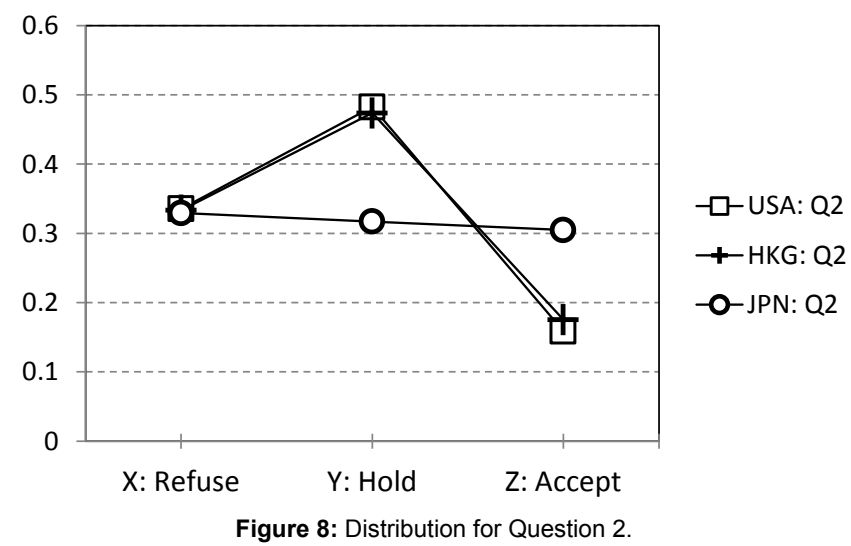


( $\mathrm{p} \sim 0.00 \%<0.1 \%)$. This means that the subject rate of the $\mathrm{X}$-group increased as the question number increased; thus, more people in the USA would be angry about their companion's action to look at a mobile phone display as the relationship with their companion was more intimate.

For Japan, the distribution in Figure 9 exhibits an inclining shape. The difference between the value of the X-group and that of the $\mathrm{Z}$-group was significantly valid, as determined using a Chi-squared test $(\mathrm{p} \sim 0.13 \%<1 \%)$. The rate value of the $\mathrm{X}$-group was small, whereas that of the Z-group was conspicuously large. The difference between the value of the Z-group for Question 1 and that for Question 3 was significantly valid, as determined using Chi-squared test ( $\mathrm{p} \sim 1.05 \%<5 \%)$. This means that the subject rate of the Z-group increased as the question number increased; thus, more people in Japan would accept their companion's action to look at a mobile phone display as the relationship with their companion was more intimate.

For Hong Kong, the distribution in Figure 9 exhibits a reversed corn-shape, whereas that in Figure 7 is a traditional corn-shape. The shape of the distribution for Hong Kong in Figure 9 appears to be midway between those of the USA and Japan. In terms of the change of rate values from Question 1 to Question 3, that of the Z-group was larger. Although the difference between the value of the X-group for Question 1 and that for Question 3 is not significant, the difference between the value of the Z-group for Question 1 and that for Question 3 was significant, as determined using a Chi-squared test $(\mathrm{p} \sim 1.93 \%<5 \%)$. This suggests that categorization into the Z-group in Hong Kong was nearly equivalent to that in Japan, although it was a little weaker than that in Japan.

It should be remarked that the change in the rates for the question number did not directly indicate the rates of transferred informants. In fact, if some informants transferred from the Y-group to the Z-group due to the change in companion and the same number of others changed in the opposite manner, then the change should be offset. This means that the rate of the transferred informants were more than the variation of the rates. There were many informants who changed their judgments based on intimacy, and the distribution in the figures presents the general tendency.

\section{The power relation}

Nakamura examined the power of sight according to the action to look at a mobile phone display during the mobile phone era [9]. $\mathrm{He}$ referred to the power of sight line in the work of Goffman and Foucault and the action has reversed the power relationship between an actor

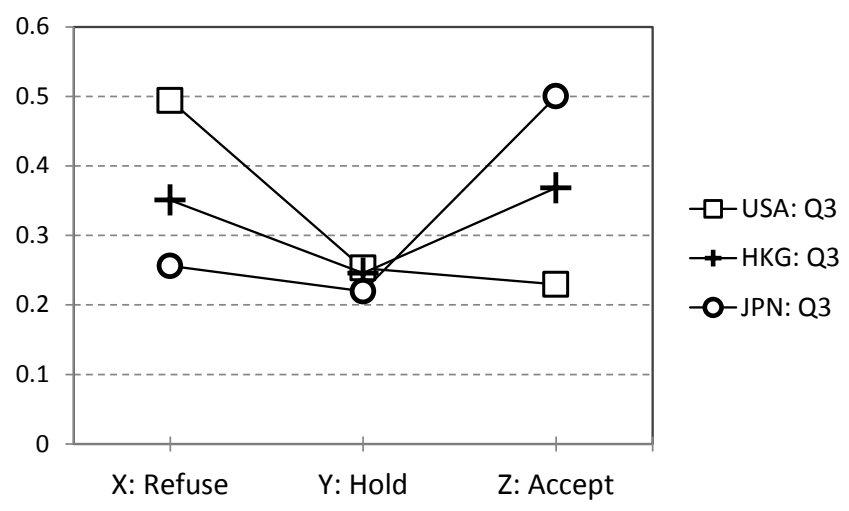

Figure 9: Distribution for Question 3. and an observer $[10,13]$. That is, 'observers remain unable to readily detect what an actor is thinking at the moment of use' and 'in face-toface communication in the mobile phone era, it is the observer who is disciplined' [9]. The weakness of an observer is caused by 'double concealment'; thus, he/she cannot know about both the onscreen image and the intention of the actor. Consequently, he/she loses the initiative in the informational power game, and he/she is compelled to await the actor's next move.

Such an informational power game should explain why the informant rates of the 'Holding' (Y-Group) were the highest in Question 1 and decreased as the question number increased for all three countries. Along with the informational game, which should be common among the three countries, the observer, who is weaker than the actor, should be even weaker if the observer does not know much about the 'co-present' actor. Thus, the observer would be apt to hold his/her decision and belong to the Y-group when the actor is one of plural friends. Conversely, some observers should cease to withhold their decisions and judge definitively if the actor is more intimate, such as a family member. The decrease in the informant rate of the Y-group can be explained by the intimacy between an actor and an observer along the power relation.

\section{Cultural difference}

As mentioned in the section 'Western and non-western culture', the concept of self is different in many ways between Western and nonWestern culture. In the following two sections, it should be theoretically supposed that both cultures differed in receiving the mobile phone usage of intimate persons, and the difference was more pronounced when the relationship was more intimate.

As shown in Figure 9 (Question 3), the distribution for the USA was declining, that for Japan was inclining, and that for Hong Kong was intermediate, although the distributions for the three countries are similar in Figure 7 (Question 1). As the relationship with the companion became more intimate, the distributions for the three countries differed more prominently. Thus, it can be considered that such diversity was caused by the cultural difference, which should be strongly associated with respective selves.

As discussed, the action to look at a mobile phone display should be predicted to be competitive in Western culture, and the Western self should feel hostile to the companion's action if the companion is intimate. More informants in the USA became angry about the action when the companion was more intimate. As mentioned, the action should be predicted to be compatible in non-Western culture, and the non-Western self should regard the companion's action when the companion is intimate. The companion's identity cannot be separated from his/her social relationships and/or mobile phone use. More informants in Japan accepted the action when the companion was more intimate. Thus, it can be concluded that the action to look at a mobile phone display is influenced by both culture and self.

This paper focuses on the judgments of the familiar person's action to look at a mobile phone display and compares three countries crossculturally. Young females were chosen as informants. They provided their impressions regarding the action according to three situations (with plural friends, with a close friend and with families). Their judgments were divided into three categories ('Refusal' (X-group), 'Holding' (Y-group) and 'Acceptance' (Z-group)) through the procedure explained. In the situation with plural friends, the distributions were 
almost the same among the three countries, and the highest rate was that of the Y-group. Conversely, in the situation with families, the distributions of the three countries were different. The group with the highest rate in the USA was the X-group, and that in Japan was the Z-group.

The difference can be explained by self-construal in Western and Non-western culture. If an independent self was going to develop/ maintain a relationship with a 'co-present' person, he/she would often feel hostile toward the action. The feelings of the independent self could be associated with the user's relationships with other people elsewhere and the fact that the user could interrupt eye contact and disturb face-to-face communication at any time. In contrast, in the case of an interdependent self, he/she would often accept the use of a mobile phone and adjust him/herself to help develop/maintain the companion's social relationships successfully. This is because a mobile phone should support the user's sociality and self-definition. Thus, the action was 'competitive' in Western culture and 'compatible' in nonWestern culture. The action to look at a mobile phone display as a form of nonverbal behavior/communication should have been influenced by the user's own culture and self.

The methodological point in this paper is that open-ended questions were asked. Some informants answered correctly, and others mentioned the presumed reason or the conditional limit. Such overdescriptions, which were causally related to the actor's decisions, should be considered to reflect the ambiguity of the action to look at a mobile phone display. Whether the method can be applied to the survey about the interpretation of an equivocal and/or ambiguous phenomenon should be discussed.

Ling discussed the 'taken for grantedness' of mobile phones. He referred to the process of becoming familiar with a clock, a car and a mobile phone [31,32]. These objects emerged in our society with new technologies. After changing the underlying structure of society, they have been arranged by 'social ecology' to intrude into our daily lives. Above all, 'a mobile phone is increasingly a vital part of our being social' and 'it is disappearing into "taken for grantedness"'. The action to look at a mobile phone display has become common in the world, and it has been taken for granted in daily life. Thus, people might overlook various types of phenomena with mobile phones, including the action. However, as mentioned above, the meaning of the action depends on intimacy for many people and the culture. Through countless iterations of the action, it has been arranged by 'social ecology' and has invaded our social life and culture $[33,34]$.

Practically, we should pay attention to such cultural features to be familiar with people in different cultures. In the mobile phone era, we charge our mobile phones with various roles in our daily lives and we frequently look at the display without negative intentions. However, people receive the action with their own criteria regarding social relationships. In front of people in different cultures, the action could cause some degree of lapse and disgrace. It should be taken to heart that the action is nonverbal behavior/communication that is associated with sociality.

This survey presents issues beyond a simple cross-cultural comparison. The action to look at a mobile phone display as a form of nonverbal behavior/communication seems to be similar when it is taken for granted; however, it deeply concerns people's sociality and self in an intimate sphere. Figures 2 and 3 illustrate self-construal, including mobile phone use for independent self and interdependent self. The analysis enabled us to estimate how deeply the technology of mobile phone communication invades a culture and self. Our results suggest that in the mobile phone era, cross-cultural comparison can provide an insight into our intimate spheres. Of course the views in Figures 2 and 3 could be reconstructed if some social functions would be added to (or lost from) a mobile phone and become fixed in human relationships in future. More observations should be needed to understand our cultures and selves.

\section{References}

1. Gauld CS, Lewisb I, Whitea KM (2014) Concealed texting while driving What are young people's beliefs about this risky behaviour? Safety Science 65: 63-69.

2. Huth V, Sanchez Y, Brusque C (2015) Drivers' phone use at red traffic lights: A roadside observation study comparing calls and visual-manual interactions. Accident Analysis \& Prevention 74: 42-48

3. Yannis G, Laiou A, Papantoniou P, Christoforou C (2014) Impact of texting on young drivers' behavior and safety on urban and rural roads through a simulation experiment. J Safety Research 49: 25-31.

4. Schwebel DC, Stavrinos D, Byington KW, Davis T, O'Neal EE, et al. (2012) Distraction and pedestrian safety: How talking on the phone, texting, and listening to music impact crossing the street. Accident Analysis \& Prevention 45: 266-271.

5. Turkle S (2011) Alone together: Why we expect more from technology and less from each other. Basic Books, New York.

6. de Souza e Silva A, Frith J (2012) Mobile interfaces in public spaces. Routledge, New York

7. Farman J (2012) Mobile interface theory. Routledge, New York.

8. Nakamura T (2007) 'Looking at "Keitai" (Mobile phone) Displays as a form of non-verbal communication. J of Japan Information-Culturology Society 14: 31-38 (in Japanese)

9. Nakamura T (2015) The action of looking at a mobile phone display as nonverbal behavior/communication: A theoretical perspective, Computers in Human Behavior 43: 68-75.

10. Goffman E (1959) The presentation of self in everyday life. Doubleday: Garden City New York.

11. Ayaß R (2014) Using media as involvement shields. J Pragmatics 72: 5-17.

12. Goffman E (1963) Behavior in public places. Free Press, New York

13. Nakamura T, Oe H (2009) Looking at "Keitai" (Mobile Phone) displays' as a form of non-verbal behavior in public spaces. The Info-socionomics Society 4 :27-37 (in Japanese)

14. Nakamura T (2013) Refusal, holding and allowance of non-verbal communication Looking at 'Keitai' displays. The Info-socionomics Society 7 (in Japanese).

15. Knapp ML, Judith AH, Terrence GH (2013) Non-verbal communication in human interaction International revised, (8thedn) Wadsworth Publishing, in Belmont, CA.

16. Argyle M, Dean J (1965) Eye-contact, Distance and affiliation. Sociometry 28 289-304.

17. Hall ET (1966) The hidden dimension, Garden City, NY: Doubleday.

18. Kendon A (1967) Some functions of gaze direction in social interaction. Acta Psychologica 26: 22-63.

19. Patterson ML (1983) Nonverbal behavior: A functional perspective. SpringerVerlag, New York.

20. Ekman P (2003) Emotions revealed: Recognizing faces and feelings to improve communication and emotional life. Times Book, New York.

21. Barnlund DC (1989) Public and private self in Japan and USA: Communicative styles of two cultures (Reprint), Intercultural Press, Boston.

22. Markus HR, Kitayama S (1991) Culture and the self: Implications for cognition emotion, and motivation. Psychological review 98: 224-253.

23. Hall ET (1976) Beyond culture. Anchor Press/Doubleday, New York.

24. Gudykunst WB, Nishida T (1994) Bridging Japanese/North American Differences. Sage. 
Citation: Nakamura T, Acar A, Ng M (2016) Cultural Comparison for the Action of Looking At a Mobile Phone Display Focusing on Independent/ Interdependent Self. Bioceram Dev Appl 6: 095. doi: 10.4172/2090-5025.1000095

Page 9 of 9

25. Hofstede GH (2001) Culture's consequences: Comparing values, behaviors, institutions and organizations across nations. Sage.

26. Nisbett R (2004) The geography of thought: How Asians and Westerners think differently and Why. Free Press.

27. Shellenbarger $S$ (2013) Just look me in the eye already-The workplace perils of staring at our phones and elsewhere; The ideal gaze lasts 7 to 10 seconds. The Wall Street Journal (28/May/2013).

28. Forgays DK, Hyman I, chreiber J (2014) Texting everywhere for everything: Gender and age differences in cell phone etiquette and use. Computers in Human Behavior 31: 314-321.

29. Chen YF, Katz JE (2009) Extending family to school life: College students' use of the mobile phone. Int J Hum-Comp Stud 67: 179-191.
30. Tufféry S (2011) Data mining and statistics for decision making. Wiley Press, UK.

31. Foucault M (1995) Discipline \& punish: The birth of the prison (2ndedn) Vintage, New York.

32. Ling R (2012) Taken for granted: The embedding of mobile communication into society. MIT Press, Cambridge, MA.

33. ITU official page, Statistics (2015) Committed to connecting the world. Global ICT developments.

34. IDC press release, (2014) Worldwide smartphone growth forecast to slow from a boil to a simmer as prices drop and markets mature, according to IDC, 01 Dec 2014. 